\title{
IDEOLOGIAS EM QUESTÕES DE PROVA DE PORTUGUÊS: UMA ANÁLISE DISCURSIVA CRÍTICA
}

\author{
Gabriel Valdez Foscaches \\ Carmem Jená Machado Caetano
}

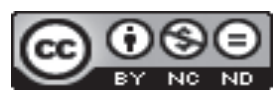

Esta obra está bajo una licencia Creative Commons

Reconocimiento-No Comercial-Sin Obra Derivada 



\title{
IDEOLOGIAS EM QUESTÕES DE PROVA DE PORTUGUÊS: UMA ANÁLISE DISCURSIVA CRÍTICA
}

\author{
IDEOLOGIES IN PORTUGUESE TEST QUESTIONS: A CRITICAL \\ DISCOURSE ANALYSIS
}

\author{
Gabriel Valdez Foscaches \\ Carmem Jená Machado Caetano
}

\begin{abstract}
RESUMO
Com este trabalho, temos por escopo evidenciar as atuais ideologias sobre a língua presentes nas avaliações, concretizadas no gênero discursivo questão de prova. Para isso, elegemos como corpus de pesquisa uma questão de prova do Enem - Exame Nacional do Ensino Médio, uma do Enade - Exame Nacional de Desempenho dos Estudantes do Ensino Superior e uma do concurso para professor da educação básica do estado de São Paulo. Selecionamos essas questões com base em seu tema comum: variação linguística. Como ferramenta de análise, adotaremos as categorias de operação da ideologia fornecidas por Thompson (2002), a fim de detectar as ideologias sobre a língua presentes nos textos selecionados. Assim, tomaremos como referencial teórico Chouliaraki \& Fairclough (1999), no que concerne ao método-teoria da Análise de Discurso Crítica; Thompson (2002), em relação à concepção de ideologia que adotaremos; e Bagno (2011), no que diz respeito à discussão sobre norma(s). Com esse aparato teórico-metodológico, mostraremos como a abordagem da variação linguística pode sustentar ideologias (relações de dominação) quando baseada no modelo de adequação linguística.

Palavras-chave: Ideologia, Análise de Discurso Crítica, Gênero Discursivo, Questão de Prova, Adequação Linguística.
\end{abstract}

\begin{abstract}
With this work, we have as a scope to highlight the current ideologies about the language present in tests, embodied in the "test question" discursive genre. Our research corpus consists of one question from Enem, Brazil's National High School Exam, one question from Enade, Brazil's National Exam of Graduating Students Performance, and one question from the test through which primary school teachers compete for a position in the state of São Paulo. We selected these three questions based in its common theme: linguistic variation. As an analysis tool, we will adopt the operating categories of ideology provided by Thompson (2002) in order to detect the ideologies about language present in the selected texts. So, we will use as theoretical reference Chouliaraki \& Fairclough (1999), regarding the theory-method of Critical Discourse Analysis; Thompson (2002), in relation to the conception of the ideology that has been adopted; and Bagno (2011), in regard to the discussion of rule(s). With this theoretical and methodological apparatus, we will show how the approach to linguistic variation can sustain relations of domination/ideologies when based on linguistic adequacy model.
\end{abstract}

Key words: Ideology, Critical Discourse Analysis, Discursive Genre, Test Question, Linguistic Adequacy.

\footnotetext{
M.L. Gabriel Valdez Fosaches. Universidade de Brasília. Programa de Pós-Graduação em Linguística (PPGL) do Departamento de Linguística, Português e Línguas Clássicas (LIP). Brasília.

Correo electrónico: gbvafo@gmail.com
}

Dra. Carmem Jená Machado Caetano. Universidade de Brasília. Programa de Pós-Graduação em Linguística (PPGL) do Departamento de Linguística, Português e Línguas Clássicas (LIP). Brasília.

Correo electrónico: carmemjena@gmail.com

Recepción: 26- 09- 2016

Aceptación: 25- 10- 2016 


\section{Qual ideologia?}

Ao se iniciar uma discussão sobre ideologia, a primeira coisa a ser feita é deixar claro qual o referencial teórico adotado. Em sua obra, Eagleton (1997, p. 15) inicia a apresentação de ideologia com dezesseis ${ }^{1}$ possíveis definiç̧̃̃es do conceito. Boa parte dessas definições são incompatíveis entre si, o que nos dá uma boa percepção de como o conceito é complexo e precisa ser discutido com critério.

Os critérios para a definição de ideologia são os mais diversos. Alguns teóricos voltam-se mais para as questões epistemológicas (verdade ou falsidade das ideias), enquanto outros se preocupam mais com a função da ideologia na vida social, isto é, com suas consequências políticas e sociais. Alguns dão ao conceito um sentido negativo e o associam sempre à dominação e exploração, outros preferem dar maior amplitude ao termo e, desta forma, neutralizá-lo politicamente.

Apesar de a ideologia, na maioria das vezes, estar relacionada com as ideias de determinado grupo, os enfoques dados a ela variam de teoria para teoria, inclusive dentro da Análise de Discurso Crítica (ADC). Por exemplo, van Dijk (2005, p. 11), diferentemente de nós - que nos filiamos à $\mathrm{ADC}$ de Fairclough -, não considera que as ideologias são necessariamente negativas, uma vez que, segundo ele, "há ideologias racistas, assim como há ideologias antirracistas, comunistas e anticomunistas".

Podemos observar, pois, que o conceito amplo de ideologia, adotado van Dijk (2005), se aproxima do conceito de ideário de Chaui (2001), que pode ser definido nos seguintes termos: conjunto sistemático organizado de ideias. Para Chaui, contudo, a ideologia não representa um ideário qualquer, mas sim um ideário histórico, social e político, que oculta a realidade de forma a manter as relações de dominação. Dessa forma, Chaui, assim como Chouliaraki \& Fairclough (1999) e Thompson (2002), define ideologia por um prisma negativo e restrito. A fim de deixarmos mais claro o que significa esse conceito negativo e restrito de ideologia, faremos uma breve retrospectiva do termo.

\section{Voltando à origem do termo}

Segundo Thompson (2002), em 1796 Destutt de Traci usou pela primeira vez o termo "ideologia", que, naquela época, significava literalmente: ciência das ideias. Nesse primeiro momento, a ideologia tinha a intenção de ser "positiva, útil e capaz de ser rigorosamente exata" (Thompson, 2002, p. 48). Por essa perspectiva, a ideologia criaria as bases para o assentamento do conhecimento científico, proporcionando uma descrição sistemática do funcionamento das ideias. Com o tempo, porém, o termo adquiriu uma conotação negativa, principalmente em decorrência das investidas difamatórias de Napoleão Bonaparte contra os ideólogos, devido à ligação desses últimos com o repubicanismo.

De acordo com Chaui, o sentido pejorativo do termo ideologia adveio da seguinte declaração de Napoleão, num discurso ao Congresso de Estado em 1812:

\footnotetext{
Todas as desgraças que afligem nossa bela França devem ser atribuídas à ideologia, essa tenebrosa metafísica que, buscando com sutilizas as causas primeiras, quer fundar sobre suas bases a legislação dos povos, em vez de adaptar as leis ao conhecimento do coração humano e às lições de história. (Chaui, 2001, p. 27)
}

Assim, a ciência das ideias passou a ser associada a abstrações e ilusões incompatíveis com a realidade. 
Posteriormente, Marx garantiu lugar de destaque para o conceito de ideologia em seu sistema teórico. No entanto, como explica Thompson (2002), sua abordagem pouco clara e ambígua ajudou a criar a confusão daquilo que se entende por ideologia ainda hoje. O autor identifica em Marx três concepções de ideologia que se distinguem e por vezes se sobrepõem: polêmica $^{2}$, epifenomênica ${ }^{3}$ e latente ${ }^{4}$. Mesmo que tenha trabalhado o conceito de ideologia de maneiras distintas e com concepções diversas, Marx, da mesma forma que Napoleão, manteve o viés negativo do conceito.

Thompson (2002) observa que após Marx houve uma tendência à neutralização da ideologia, isto é, as ideias de que a ideologia representava o interesse das classes dominantes foram estendidas. Por exemplo, conforme observa Eagleton (1997), nos escritos de Lenin e Lukács, o termo passou a ser usado em sentidos mais amplos (e.g. "ideologia do proletariado" e "ideologia socialista"), sem necessariamente estar relacionado à assimetria de poder.

Também preocupado com o tema da ideologia, Mannheim (1972) propôs, ao desenvolver seus estudos na "sociologia do conhecimento", que a concepção particular de ideologia (que se refere ao nível dos enganos e das mentiras dos opositores) deveria ser substituída por uma concepção geral (na qual o foco está nas características gerais do pensamento de uma época ou de um grupo sócio-histórico).

Considerando todas essas definições, Thompson (2002) faz a distinção entre dois tipos de concepção de ideologia: neutra e crítica. A primeira possui um teor mais descritivo, isto é, nesta concepção a ideologia pode servir tanto para a manutenção como para a preservação da ordem social. Gouveia explica melhor esta concepção:

\footnotetext{
Numa concepção que procura ser de teor meramente descritivo, a ideologia refere-se a sistemas de pensamento, de valores e crenças, por exemplo, que denotam um ponto de vista particular sobre o real, uma construção social da realidade, independentemente de aspirarem ou não à preservação ou à mudança da ordem social. (Gouveia, 2002, p. 338)
}

Na concepção neutra, a ideologia não necessariamente implica uma falsa consciência da realidade, pois ela é uma forma particular de interpretação da realidade. Não se trata, portanto, de uma ofuscação da verdade real.

No que se refere às concepções críticas de ideologia, elas, "diferentemente das concepções neutras, implicam que os fenômenos caracterizados como ideológicos são enganosos, ilusórios ou bilaterais" (Thompson, 2002, p. 82). O uso das concepções críticas, portanto, traz um sentido negativo aos fenômenos tidos como ideológicos.

Com base no que vimos até agora, podemos dividir os autores que trabalharam com o termo ideologia da seguinte maneira, conforme propõe Thompson (2002):

\section{Quadro 1. Concepções Críticas e não críticas de ideologia}

\begin{tabular}{|l|l|}
\hline Concepções críticas & Concepções neutras \\
\hline Napoleão & Destutt de Tracy \\
Marx & Lennin \\
Mannheim (concepção particular & Lukás \\
de ideologia) & Mannheim (concepção geral de ideologia) \\
\hline
\end{tabular}

Fonte: Thompson, 2002 (adaptado). 


\section{Ideologia segundo Thompson}

Feita essa retrospectiva, cumpre frisar a concepção de ideologia que adotaremos: a concepção crítica/negativa proposta por Thompson (2002). O autor propõe, inspirado na concepção de ideologia latente de Marx, sua própria definição: "estudar a ideologia é estudar as maneiras pelas quais o significado serve para estabelecer e sustentar as relações de dominação" (Thompson, 2002, p. 85). Nessa concepção, os fenômenos ideológicos são fenômenos simbólicos que servem para sustentar relações de dominação; os fenômenos ideológicos, contudo, não necessariamente são ilusórios. Não se trata de definir a verdade ou falsidade dos fenômenos ideológicos, mas de entender como os fenômenos simbólicos servem para perpetuar as relações de dominação.

Thompson (2002) propõe, então, cinco modos gerais de operação da ideologia: 1) legitimação - formas simbólicas são apresentadas como justas e dignas de apoio; 2) dissimulação - formas simbólicas são apresentadas de modos que desviam a atenção; 3) unificação construção de uma identidade coletiva, independentemente da diferenças individuais e sociais; 4) fragmentação - segmentação dos grupos ou indivíduos que possam significar ameaça aos grupos detentores do poder; e 5) reificação - processos são tratados como coisas.

Além dos modos gerais, existem estratégias típicas -subcategorias dos modos geraisde operação da ideologia, quais sejam:

Legitimação:

1.1) racionalização: construção de uma cadeia de raciocínios que visam defender ou justificar um conjunto de relações ou instituições sociais e, assim, ganhar o apoio do público pela persuasão;

1.2) universalização: acordos institucionais que servem aos interesses de poucos indivíduos são representados como se servissem ao interesse de todos. Tais acordos são considerados, em princípio, abertos a qualquer que tenha a capacidade e inclinação para triunfar neles;

1.3) narrativização: As exigências se inserem em histórias que recontam o passado e que narram o presente como parte de uma tradição imemorial e apreciada. De fato, às vezes se inventam tradições a fim de criar uma sensação de pertencimento a uma comunidade e história que transcende a experiência de conflito, diferença e divisão.

2) Dissimulação:

2.1) deslocamento: Um termo que geralmente se usa para referir-se a um objeto ou indivíduo é empregado para referir-se a outro. Em consequência, as conotações positivas ou negativas se transferem ao outro objeto ou indivíduo;

2.2) eufemização: As ações, instituições ou relações sociais são descritas em termos que geram uma valoração positiva;

2.3) tropo: Uso figurado da linguagem ou, mais amplamente, das formas simbólicas. Entre as formas de tropo mais usadas, estão a metonímia, a sinédoque e a metáfora. A sinédoque implica a combinação semântica da parte pelo todo. A metonímia refere-se ao uso de um termo que representa um atributo, uma característica relacionada a algo para referir-se à própria coisa ainda que não exista relação entre eles. Por fim, a metáfora implica a aplicação de um termo ou frase a um objeto ou ação ao qual literalmente não pode ser aplicado.

3) Unificação:

3.1) padronização: As formas simbólicas se adaptam a um marco de referência padrão que é promovido como a base aceitável e comum das trocas simbólicas; 
3.2) simbolização da unidade: Esta estratégia implica a construção de símbolos de unidade, de identidade coletiva e de identificação, que se difunde em um grupo em uma pluralidade de grupos.

4) Fragmentação:

4.1) diferenciação: Dá-se ênfase às distinções, diferenças e divisões existentes entre os grupos e indivíduos;

4.2) expurgo do outro: Refere-se à construção, dentro ou fora, de um inimigo que é retratado como maligno, daninho ou ameaçador. Assim, os indivíduos são convocados para resistir a ele ou expurgá-lo.

5) Reificação:

5.1) naturalização: Refere-se a um estado de coisas (que seja uma criação social ou histórica) que passa a ser tratado como resultado inevitável das características naturais, e.g., fisiológicas;

5.2) eternalização: Os fenômenos históricos são privados de seu caráter histórico ao serem tratados como permanentes, invariáveis e sempre recorrentes;

5.3) nominalização/passivação: Os processos/acontecimentos são representados sem que os atores das ações sejam explicitados.

$\mathrm{O}$ autor frisa que essas não são as únicas maneiras de operação da ideologia e que não necessariamente operam de modo independente. No entanto, essas estratégias só serão ideológicas, é importante repetir, se servirem para sustentar relações de dominação. Aliás, como observa Chaui (2001, p. 110), "falar em ideologia dos dominados é um contra-senso, visto que a ideologia é um instrumento de dominação".

Com base nas categorias de Thompson, analisaremos as questões de prova.

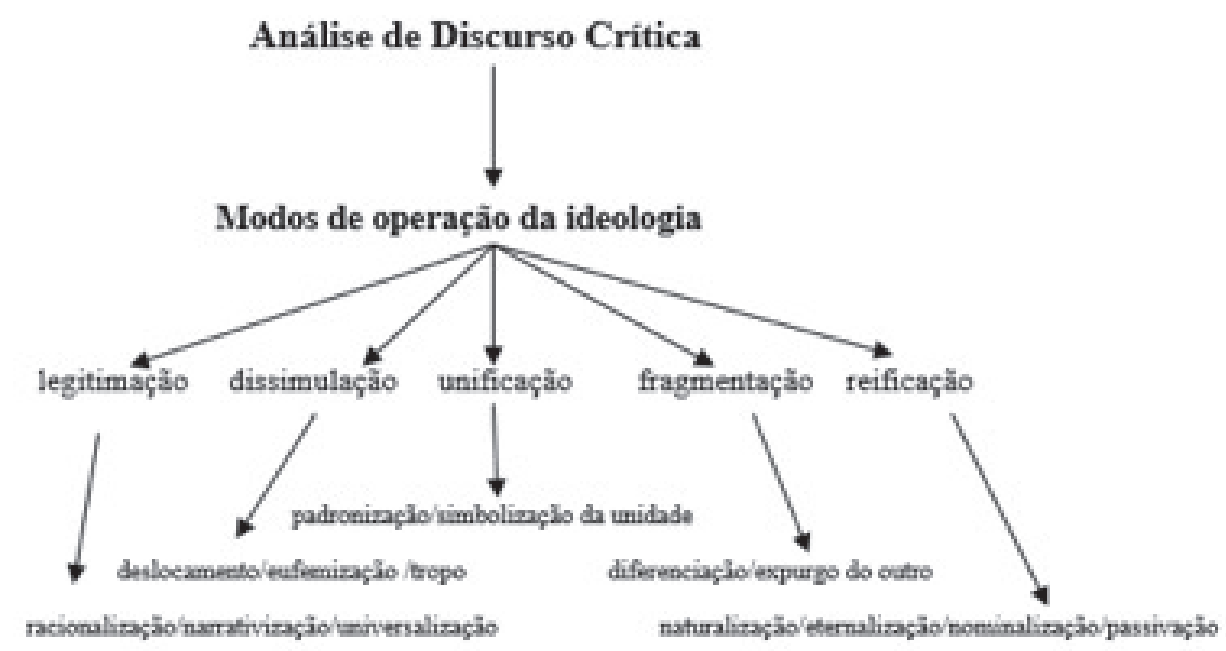

Figura 1. Modos de operação da ideologia

Fonte: Elaboração do autor 


\section{Ideologias nas questões de prova}

Neste artigo, não discutiremos a ideologia em um vácuo social, mas sim em um espaço bem específico e familiar para boa parte das pessoas letradas, qual seja: em questões de prova.

Conforme observa Luckesi (2008), o estabelecimento do ensino hoje está centrado no resultado das provas e exames. Por isso, o gênero questão de prova se mostra um poderoso instrumento para o exercício de poder e para disseminação de ideologias. De acordo com Soares (1991), através da avaliação, realizada pela questão de prova, é possível exercer o controle sobre o conhecimento, na medida em que se define: 1) o que deve ser sabido; 2) se o avaliado sabe tudo o que se deve saber e apenas o que se deve saber; e 3) se sabe tal como se deve saber. A avaliação define, então, as realizações válidas de conhecimento de quem ensina e de quem é ensinado (Berstein, 1996).

As avaliações não cobram um conhecimento qualquer, mas sim o conhecimento baseado na cultura das classes privilegiadas (Bourdieu \& Passeron, 1970). Isso se torna especialmente claro ao falarmos de língua, como veremos a seguir.

Muitas pesquisas foram feitas mostrando como a avaliação serve de instrumento para a seleção social (Bourdieu \& Passeron, 1970; Perrenoud, 1999; Luckesi, 2008; Freitas \& Fernandes, 2007; Soares, 1991). Nosso trabalho terá um foco um pouco diferente. Apesar de também estarmos preocupados com as relações de dominação que as avaliações podem manter, nosso escopo será a análise, com base nas categorias de Thompson, dos discursos ideológicos veiculados no gênero discursivo questão de prova.

Analisaremos, então, três questões. A primeira é a questão do Exame Nacional do Ensino Médio (Enem), que agora serve (também) como um processo seletivo para a entrada no ensino superior. A segunda questão é do Exame Nacional de Desempenho de Estudantes (Enade), que avalia os alunos que já estão no ensino superior. E a terceira questão foi retirada de um concurso para professor da educação básica de São Paulo - processo seletivo para aqueles que já terminaram o ensino superior.

Essas três questões representam três etapas na vida de um estudante de Letras: 1) ao sair do ensino médio e ingressar na universidade; 2) ao entrar/sair da universidade; e 3) ao ingressar no mercado de trabalho. Selecionamos essas questões com base em seu tema comum: variação linguística.

Por não haver espaço hábil que permita a explicação de outros métodos da Análise de Discurso Crítica - como a Linguística Sistêmico-Funcional - e pelo nosso foco ser a ideologia neste artigo, nos ateremos ao uso das categorias de análise de Thompson (2002).

\section{Análise das questões de prova}

\subsection{Questão de prova do Enem}

\section{Entrevista com Marcos Bagno}

Pode parecer inacreditável, mas muitas das prescrições da pedagogia tradicional da língua até hoje se baseiam nos usos que os escritores portugueses do século XIX faziam da língua. Se tantas pessoas condenam, por exemplo, o uso do verbo "ter" no lugar de "haver", como em "hoje tem feijoada", é simplesmente porque os portugueses, em dado momento da história de 
sua língua, deixaram de fazer esse uso existencial do verbo "ter". No entanto, temos registros escritos da época medieval em que aparecem centenas desses usos. Se nós, brasileiros, assim como os falantes africanos de português, usamos até hoje o verbo "ter" como existencial é porque recebemos esses usos de nossos ex-colonizadores. Não faz sentido imaginar que brasileiros, angolanos e moçambicanos decidiram se juntar para "errar" na mesma coisa. E assim acontece com muitas outras coisas: regências verbais, colocação pronominal, concordâncias nominais e verbais etc. Temos uma língua própria, mas ainda somos obrigados a seguir uma gramática normativa de outra língua diferente. Às vésperas de comemorarmos nosso bicentenário de independência, não faz sentido continuar rejeitando o que é nosso para só aceitar o que vem de fora. Não faz sentido rejeitar a língua de 190 milhões de brasileiros para só considerar certo o que é usado por menos de dez milhões de portugueses. Só na cidade de São Paulo temos mais falantes de português que em toda a Europa!

Informativo Parábola Editorial, s/d $\mathrm{Na}$ entrevista, o autor defende o uso de formas linguísticas coloquiais e faz uso da norma padrão em toda a extensão do texto. Isso pode ser explicado pelo fato de que ele

\section{a) adapta o nível de linguagem à situação comunicativa, uma vez que o gênero entrevista requer o uso da norma-padrão.}

b) apresenta argumentos carentes de comprovação científica e, por isso, defende um ponto de vista difícil de ser verificado na materialidade do texto.

c) propõe que o padrão normativo deve ser usado por falantes escolarizados como ele, enquanto a norma coloquial deve ser usada por falantes não escolarizados.

d) acredita que a língua genuinamente brasileira está em construção, o que o obriga a incorporar em seu cotidiano a gramática normativa do português europeu.

e) defende que a quantidade de falantes do português brasileiro ainda é insuficiente para acabar com a hegemonia do antigo colonizador.

Disponível em: <http://inep.gov.br/>. Acessado em 6 de nov. de 2014.

Apesar de trazer à tona o tema da variação linguística, o elaborador da questão promove a reificação, dissimulação e legitimação de uma ideologia, conforme veremos a seguir.

O texto-base da questão, de autoria de Marcos Bagno, trata do uso do verbo "ter" no português brasileiro. Ainda que o texto-base aborde a variação linguística por uma perspectiva não discriminatória, o enunciado e as alternativas da questão reproduzem a confusão existente entre os conceitos de norma culta e norma-padrão, confusão desfeita pelo próprio Bagno em suas obras. Enquanto a norma culta é aquela que os falantes letrados usam em ambientes de alto grau de monitoramento (Bagno, 2011), a norma-padrão pode ser definida como “[...] uma codificação relativamente abstrata, uma baliza extraída do uso real para servir de referência, em sociedades marcadas por acentuada dialetação, a projetos políticos de uniformização linguística" (Faraco, 2008, p. 75).

Em outras palavras, a norma-padrão não é uma das variedades empiricamente observáveis numa língua. Sobre a norma-padrão, Bagno (2007, p. 98) pontua:

Ela é um construto sociocultural, uma norma no sentido mais jurídico do termo, uma espécie de lei

"linguística" que prevê a condenação e a punição dos infratores. Por isso, não é correto usar os termos "língua-padrão", variedade-padrão", "dialeto-padrão", porque não existe língua, variedade e dialeto sem falantes reais, e ninguém fala a norma-padrão. 
Assim, Bagno não usa a norma-padrão em seu texto. Ao ignorar essa diferença teórica, o elaborador racionaliza a padronização linguística. Analisemos a lógica da qual o elaborador lança mão. Sua tese é de que "o autor [Bagno] defende o uso de formas linguísticas coloquiais e faz uso da norma padrão em toda a extensão do texto". Segundo o elaborador "isso pode ser explicado pelo fato de que ele adapta o nível da linguagem à situação comunicativa". Ainda de acordo com o elaborador, Bagno adapta o nível da linguagem à situação comunicativa "uma vez que o gênero entrevista requer o uso de norma-padrão". Assim, o elaborador nos faz chegar à seguinte conclusão: é necessário adequar a linguagem à situação comunicativa.

O problema do modelo de adequação é que ele naturaliza a realidade linguística. Isto é, o elaborador apresenta o gênero discursivo como se fosse uma entidade natural, e não como um fenômeno social - diremos o como e o porquê a seguir.

Em "o gênero entrevista requer o uso da norma padrão" é possível notar a dissimulação da ideologia que naturaliza a imposição da norma-padrão. Por meio do tropo, os atores sociais aparecem impersonalizados. Em outras palavras, o "gênero entrevista" não possui o traço semântico [+ humano] para exercer a ação. Dessa forma, os atores sociais que, de fato, demandam o uso da norma-padrão - os detentores de maior poder social - são reificados. A exclusão dos atores sociais dá a impressão de que a necessidade de adequação linguística é um "fato" incontornável, que independe da agência humana.

Ora, essa visão da realidade linguística é demasiado determinista. Em nossa perspectiva, as estruturas sociais só se reproduzem em decorrência da agência das pessoas (Fairclough \& Fairclough, 2012), e a agência das pessoas não é totalmente determinada pelas estruturas sociais (reificação). Portanto, sugerir que o aluno deve se subordinar às regras do gênero discursivo (socialmente construídas) porque assim são as convenções, nada mais é do que promover a naturalização das relações de dominação existentes.

Considerando que as convenções linguísticas são fenômenos sociais, é necessário aprender a escolher quando se conformar às convenções como elas são, ou desafiá-las, e assim ajudar a abrir novos caminhos (Janks \& Ivanic, 1992). No gênero discursivo entrevista para o jornal, por exemplo, é mais fácil desafiar as convenções do que no gênero discursivo entrevista de emprego, em que o entrevistado provavelmente escolherá se conformar às determinações.

Por fim, é importante refletir: se cada variante tem o seu valor, conforme se postula no modelo de adequação usado pela questão, por que as variantes não "cultas" nunca têm valor suficiente ${ }^{5}$ para serem usadas nas esferas valorizadas de comunicação?

\subsection{Questão de prova do Enade}

No meio do meu descanso, toca o telefone: "Boa tarde, senhor. Aqui é da Mega Plus International, que, por sua boa relação como cliente, vai estar disponibilizando, totalmente grátis, sem nenhum custo adicional, o Ultra Mega Plus Card, com todas as vantagens do programa especial Mega Plus Services. Vai estar também oferecendo..." Pronto, já me perdi no gerúndio desnecessário dela. Respondo: "Obrigado pela oferta, mas não vou estar querendo, já tenho outro" "Mas, senhor...", insiste a atendente, "que vantagens o seu cartão já oferece?" Respondo: "Não oferece vantagem nenhuma, mas o que rola entre a gente é uma relação sem interesse, é só amor mesmo...sabe aquele não querer mais que bem querer de Camões. A atendente de telemarketing se despede, mas não sem antes rir do outro lado da linha. 
Em casos como o do texto acima, o uso do gerúndio constitui mais o que a descrição tradicional chamaria de vício de linguagem do que propriamente uso incorreto do ponto de vista da norma padrão. Dessa forma, esse uso fere mais aspectos estilísticos que estruturais da norma. Nessa perspectiva, assinale a opção em que o enunciado apresenta o mesmo tipo de inadequação linguística.

a) O Mário, ele vive dizendo que não gosta de ir ao cinema.

b) Você sabe que tenho ainda todas as tuas anotações do caso.

c) Eu, naquele momento de susto, se senti confuso e atordoado.

d) Pediu para que seje visto o caso com maior atenção possível.

e) A vítima do estrupo deu queixas na delegacia de sua cidade

Disponível em: <http://inep.gov.br/>. Acessado em 6 de nov. de 2014.

A questão do Enade, feita por professores de Instituições de Ensino Superior, trabalha com o modelo de adequação. No enunciado da questão, discute-se o uso de variantes linguísticas não "cultas", mais especificamente as usadas pelos atendentes de telemarketing. Da mesma forma que observamos na questão anterior, esta questão está calcada na ideologia de adequação linguística.

Conforme podemos ver no comando da questão, "assinale a opção em que o enunciado apresenta o mesmo tipo de inadequação linguística", o elaborador apenas dissimula a discriminação linguística através de um léxico mais suave. Em vez de erro, falase em "inadequação" e em descaso com os "aspectos estilísticos". Ao mesmo tempo em que dissimula a discriminação, o elaborador padroniza o referencial linguístico, mostrando que variantes linguísticas não devem ser usadas (as dos atendentes de telemarketing).

Antes de prosseguir na análise do texto, passemos à estrutura do gerundismo, que fere os "aspectos estilísticos" da norma: ir (presente) + estar (infinitivo) + gerúndio. A principal controvérsia é o uso do verbo estar depois de outro verbo auxiliar. Possivelmente construções como "vou continuar trabalhando" ou "vou permanecer dormindo" não seriam criticadas. Dessa forma, nem todo uso do gerúndio fere os "aspectos estilísticos", conforme indica o gabarito da questão (alternativa "a”); contudo, mesmo as construções canônicas como "ele vive dizendo que não gosta de ir ao cinema", texto do gabarito, passaram a ser estigmatizadas, pelo simples fato de apresentarem um gerúndio, que remete à linguagem de telemarketing.

Outra questão, mais relacionada à função da construção, diz respeito ao compromisso expresso no gerundismo. Conforme analisa Possenti (2009, p. 49): “o compromisso expresso em 'vou providenciar' é mais incisivo do que o expresso em 'vou estar providenciando'. Mais ou menos como é mais incisivo dizer 'providenciarei' do que "vou providenciar".

Diante do exposto, é preciso notar como a ideologia de adequação linguística dissimula as relações de dominação que se dão por meio da língua. Os conceitos de "certo" e "errado" são trocados por "adequado" e "inadequado". Essa eufemização dissimula a estigmatização não da língua, mas de seus usuários, pois, como salienta Bagno (2011), o preconceito é contra os usuários e não contra a língua em si.

Ora, de acordo com Janks \& Ivanic (1992), a linguagem pode contribuir tanto para a reprodução quanto para a transformação social. Nessa perspectiva, o modelo de adequação, a despeito de sua terminologia suave, não contribui para a transformação das relações permeadas pela violência simbólica; pelo contrário, as perpetua. A ideologia permanece 
presente nesse modelo, pois se legitima a não aceitação das variantes não cultas a pretexto de serem linguisticamente inadequadas.

Assim, se, como mostra o enunciado da questão, a construção é estruturalmente gramatical e a intenção era combater o preconceito linguístico, o que se faz é apenas trocar a roupagem da discriminação linguística e dar-lhe um aspecto mais científico. A ideologia/ modelo de adequação linguística precisa, pois, ser reanalisada. Por essa razão, a Análise de Discurso Crítica traz a proposta de trabalho com a "Consciência Linguística Crítica":

\section{segundo a qual os (as) aprendizes deveriam ser levados a compreender as relações sociais de poder subjacentes ao uso da linguagem e os processos sociopolíticos de unificação linguística, de modo a optar entre a língua normatizada, tolerá-la estrategicamente ou contestá-la oportunamente, fortalecendo a identidade dos grupos socioeconomicamente em desvantagem. (Rios, 2014, p. 42)}

Portanto, a abordagem da variação linguística não é suficiente - como muitos talvez tenham pensado no passado - para romper as relações de dominação e empoderar os grupos dominados, principalmente quando a abordagem é feita com base no modelo de adequação linguística. Conforme mostraremos na questão a seguir, o modelo de adequação está sendo usado inclusive pelos próprios "especialistas" conservadores, que se apropriaram desse modelo para disseminar sua ideologia.

\subsection{Questão da prova para professor da educação básica de São Paulo}

Observe a charge a seguir:

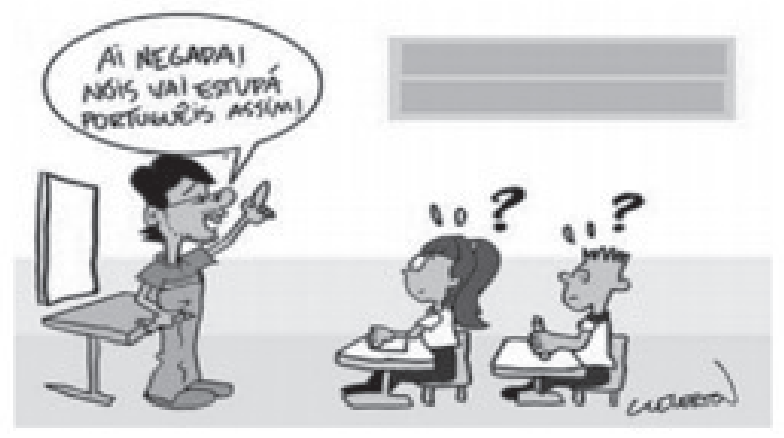

Assinale a alternativa que analisa adequadamente a situação de ensino acima representada.

a) A situação interlocutiva, por ser informal, justifica a utilização da variação utilizada pelo professor.

b) A variação linguística a ser ensinada na escola, como mostra a charge, tem que estar adequada à região do país em que essa escola se localiza.

c) As variações da língua portuguesa devem ser igualmente estudadas na escola, pois são imprevisíveis as situações comunicativas em que se vão inserir os alunos.

d) A escola, ao contrário do que pensa o professor da charge, deve dar acessibilidade à norma culta da língua, democratizando o acesso à variação de mais prestígio social.

e) O professor da charge certamente acredita que seus alunos pertencem a uma camada social de menor acesso à cultura e adota uma variação linguística que lhe permite mais interatividade. 
Esta questão foi retirada de uma prova para professor da educação básica do estado de São Paulo. De fato, a questão reconhece a existência da variação linguística, mas o faz apenas com o intuito de deslegitimá-la e padronizar o referencial linguístico, por meio da fragmentação. A ideologia inculcada pelo texto, porém, não resiste à análise linguística.

Primeiro vejamos: os conceitos de variação e variedade linguística são misturados em toda a questão, inclusive no gabarito:

\section{d) A escola, ao contrário do que pensa o professor da charge, deve dar acessibilidade à norma culta da língua, democratizando o acesso à variação de mais prestígio social.}

Onde se lê variação, deveria se ler variedade, que é um dos muitos modos de falar uma língua (Bagno, 2008), ao passo que variação diz respeito ao fenômeno de mudança da língua. Ao tentar inculcar sua ideologia, o elaborador lança mão do humor para criar a imagem de um professor alienado, ao qual os alunos da charge e os professores que estão fazendo a prova devem resistir.

Em "a escola, ao contrário do que pensa o professor, deve dar acessibilidade à norma culta", podemos constatar o expurgo do outro. Por meio dessa estratégia ideológica, fragmentam-se as pessoas, criando diferenciações em que, de um lado, estão as pessoas erradas (as que discordam do elaborador) e, do outro, estão as pessoas certas, que concordam com o elaborador da questão e que perpetuarão sua ideologia na sala de aula. Como se vê da questão, o humor não só é capaz de subverter relações de dominação, mas é capaz também de mantê-las.

Ademais, a transcrição da fala do professor ("nóis", "estudá" e "portuguêis") representa a pronúncia corrente dessas palavras, o que não se confunde com as formas prescritas pelas leis ortográficas. O apagamento do /r/ no final dos infinitivos está no vernáculo dos brasileiros, inclusive dos falantes urbanos escolarizados, isso explica a grafia: como você estar (em vez de "está")? (Bagno, 2007). Em relação ao "nóis" e "portuguêis", a vogal tônica final pode ditongar-se diante do arquifonema /S/ (Câmara, 2007). No que concerne à concordância verbal, o plural em "nó(i)s vai"6 já está marcado no pronome - da mesma forma que no francês, em que o plural redundante só existe na modalidade escrita. Assim, o texto mistura de forma estereotipada a relação entre escrita e fala.

$\mathrm{O}$ efeito de sentido de humor produzido pela charge, gênero discursivo que compõe o gênero questão de prova, camufla uma visão etnocêntrica de língua (padronizadora). A piada é possível justamente porque a variedade não culta (plural não redundante) é empregada pelo professor, mais ainda: empregada pelo professor dentro da sala de aula. Daí surge o (suposto) humor da questão. Afinal, se considerarmos que a escola reproduz os padrões culturais da classe dominante, nada é mais absurdo e risível do que achar que a "subcultura" dos dominados tenha espaço dentro da sala de aula, tendo em vista que "a linguagem é, ao mesmo tempo, o principal produto da cultura, e é o principal instrumento de sua transmissão" (Soares, 1989, p. 16).

Considerando que as variedades linguísticas são funcionalmente equivalentes e que a norma culta é referência por razões históricas e sociológicas - e não por fatores linguísticos puramente -, a questão se mostra altamente preconceituosa ao rejeitar através do humor a variedade não culta.

Segundo o elaborador, a escola "deve dar acesso à norma culta da língua, democratizando a variação de prestígio". No entanto, a escola não democratiza a língua ao impor uma variedade de prestígio, isto é, não empodera as pessoas que vivem situações de opressão linguística. Pelo contrário, muitas vezes a escola aprofunda as relações de opressão. 
Dessa forma, a aquisição da variedade linguística prestigiada não é um "direito" do aluno, mas sim uma obrigação, caso não queira sofrer discriminação. Diante disso, podemos perceber uma universalização ideológica, pois a imposição linguística é retratada como um direito do estudante, e não como uma obrigação socialmente imposta.

\section{Considerações finais}

Nas três questões apresentadas, o aluno é avaliado em relação a um modelo dominante de língua. Ainda que o nosso corpus seja pequeno, achamos que ele representa como a padronização ideológica da língua vem ocorrendo, mesmo nas questões mais atuais e progressistas - como a do Enem. A partir dos textos, vimos como as avaliações podem ser culturalmente preconceituosas. No caso das questões analisadas, a ideologia de adequação linguística foi a fonte dos preconceitos detectados.

A ideologia de adequação, conforme constatamos, propicia a discriminação social veladamente, por meio de estratégias como a eufemização e a naturalização das convenções linguísticas (padronização) - é importante frisar, todavia, que essas não são as únicas estratégias ideológicas. Analisar as relações de poder que subjazem as convenções é um passo necessário para a sua desnaturalização, pois as convenções são socialmente construídas passíveis, pois, de mudança - e arbitrariamente impostas - geradoras de violência simbólica.

Postulamos neste artigo que, após compreenderem a arbitrariedade das convenções, as pessoas poderão optar por seguir a padronização linguística, tolerá-la estrategicamente ou contestá-la em sua arbitrariedade, ajudando a criar novos caminhos para a superação da opressão linguística.

É importante salientar que não incentivamos que as pessoas não aprendam a norma culta/padrão, pois a falta de domínio dessa norma implica exclusão social. Defendemos, sim, a conscientização linguística crítica dos atores sociais, uma vez que a tomada de consciência é primeiro passo para a mudança de uma realidade linguística opressora. Conforme quisemos mostrar, a abordagem das variedades linguísticas por uma perspectiva de adequação apenas dissimula/reifica uma ideologia etnocêntrica e padronizadora. Afinal, como lembra Fairclough (1992), representar as variedades linguísticas como diferentes e condicionadas à adequação é dar à desigualdade o aspecto de diversidade.

Ao escolher essas três questões, quisemos mostrar a que ideologia estaria submetido um aluno de Letras: ao sair do ensino médio e entrar na universidade (Enem); ao entrar/sair da universidade (Enade); ao ingressar no mercado de trabalho (concurso para professor). Ademais, quisemos indicar um problema que precisa ser mais amplamente pesquisado: as ideologias atuais sobre a língua e sua manifestação em questões de prova. O foco na questão de prova se deve ao poder que pode ser exercido por meio desse gênero, visto que boa parte do que estudamos decorre daquilo que nos é exigido nas avaliações.

Assim, por mais que se tenha avançado na conscientização sobre o poder discriminatório exercido sobre e por meio da língua, ainda há muito que se avançar. O trabalho com a teoria da consciência linguística crítica (Fairclough, 1992) nos parece um caminho viável para o enfrentamento do problema.

\section{Notas}

1. O processo de produção de significados, signos e valores na vida social; b) um corpo de ideias característico de um determinado grupo ou classe social; c) ideias que ajudam a legitimar um poder 
político dominante; d) ideias falsas que ajudam a legitimar um poder político dominante; e) comunicação sistematicamente distorcida; f) aquilo que confere certa posição a um sujeito; g) formas de pensamento motivadas por interesses sociais; h) pensamento de identidade; i) ilusão socialmente necessária; j) a conjuntura de discurso e poder; k) o veículo pelo qual atores sociais conscientes entendem o seu mundo; 1) conjunto de crenças orientadas para a ação; m) a confusão entre realidade linguística e realidade fenomenal; n) oclusão semiótica; o) o meio pelo qual os indivíduos vivenciam suas relações com uma estrutura social; p) o processo pelo qual a vida social é convertida em uma realidade natural.

2. Nesta concepção, "a ideologia é uma doutrina e atividade teórica que erroneamente considera as ideias como autônomas e eficazes e que não consegue compreender as condições e características reais da vida sócio-histórica" (Thompson, 2002, p. 55).

3. Segundo a concepção epifenomênica, “a ideologia é um sistema de ideias que expressa os interesses da classe dominante, mas que representa de maneira ilusória as relações de classe" (Thompson, 2002, p. 59).

4. Segundo esta concepção, "ideologia é um sistema de representações que serve para manter as relações existentes de dominação de classe ao orientar os indivíduos para o passado mais do que para o futuro, ou para imagens ou ideais que ocultam as relações de classe e se apartam da busca coletiva da mudança social" (Thompson, 2002, p. 62).

5. Como coloca Bourdieu (1983), as variantes linguísticas funcionam como bens de valor (ou sem valor) dentro de um mercado.

6. Este plural, contudo, é socialmente estigmatizado.

\section{Bibliografia}

Bagno, M. (2007). Nada na língua é por acaso: por uma pedagogia da variação linguística. São Paulo: Parábola Editorial.

Bagno, M. (2011). Gramática pedagógica do português brasileiro. São Paulo: Parábola Editorial.

Berstein, B. (1996). Pedagogy, symbolic control, and indentity: theory, research, critique. London: Taylor \& Francis.

Bourdieu, P. A. (1983). Economia das trocas linguísticas. In Bourdieu-Sociologia, Coleção Grandes Cientistas Sociais. (Vol. 39). São Paulo: Ática.

Bourdieu, P., e Passeron, J. C. (1970). A Reprodução: Elementos para uma Teoria do Sistema de Ensino. Rio de Janeiro: Livraria Francisco Alves Editora.

Câmara Jr., J. M. (2007). Estrutura da Língua Portuguesa. Petrópolis: Vozes.

Chaui, M. (2001). O que é Ideologia. São Paulo: Brasiliense.

Chouliaraki, L., e Fairclough, N. (1999). Discourse in late modernity: Rethinking critical discourse analysis. Edinburgh: Edinburgh University.

Dijk, T. A. (2005). Ideología y análisis del discurso. Utopia y Praxis Latino Americana. 10 (29).

Eagleton, T. (1997). Ideologia. Uma introdução. São Paulo: Editora da Universidade Estadual Paulista/ Editora Bontempo.

Fairclough, N. (1992). Critical Language Awareness. London and New York: Longman.

Fairclough, I., e Fairclough, N. (2012). Political discourse analyses: A method for advanced students. London: Routledge.

Faraco, C. A. (2008). Norma culta brasileira: desatando alguns nós. São Paulo: Parábola Editorial. 
Freitas, L. C., e Fernandes, C. O. (2007). Currículo e avaliação Indagações sobre currículo. Brasília: Ministério da Educação Básica.

Gouveia, C. A. M. (2001). Análise crítica do discurso: enquadramento histórico. Por C. Correia y M. Mateus (Eds.). Saberes no tempo: homenagem a Maria Henriqueta Costa Campos. (335-351). Lisboa: Colibri.

Janks, H., e Ivanic, R. (1992). Critical Language Awareness and emancipatory discourse. Por N. Fairclough (Comp.). Critical Language Awareness. (305-331). London and New York: Longman.

Luckesi, C. C. (2008). Avalição da Aprendizagem Escolar. São Paulo: Cortêz.

Mannheim, K. (1972). Ideologia e Utopia. Rio de Janeiro: Zahar Editores.

Perrenoud, P. (1999). Avaliação: da excelência à regulação das aprendizagens, entre duas lógicas. Porto Alegre: Artmed.

Possenti, S. (2009). Língua na mídia. (1 ed.). São Paulo: Parábola Editorial.

Rios, G. (2014). Linguagem e Alfabetização de Adultos: uma perspectiva crítico-ideológica. http://www.bocc.ubi.pt/pag/rios-guilherme-linguagem-e-alfabetizacao-de-adultos.pdf. [Consulta em 13 de abril de 2014].

Soares, M. B. (1989). Linguagem e escola. São Paulo: Ática.

Soares, M. B. (1991). Avaliação educacional e clientela escolar. Por M. Patto (Ed.). Introdução à Psicologia Escolar. (47-53). São Paulo: T.A. Queiroz.

Thompson, J. B. (2002). Ideología y cultura moderna. Teoría crítica social en la era de la comunicación de masas. (2 ed.). México: Universidad Autónoma Metropolitana. 